\title{
The Emotional Burden of COVID 19 in Frontline Health Care Workers at A Tertiary Care Hospital in Pakistan
}

Muhammad Siddique Kakar, Shehzad Rauf, Umer Jalal, Waseem Ahmed Khan, Isbah Gul

- - - - - - - - - - - - - - - - - - - - - - - - - - - - ABSTRACT

Objective: To assess the levels of depression, anxiety and stress in frontline health care workers dealing with COVID 19 patients.

Study Design and Setting: This cross-sectional study was conducted at PNS Shifa hospital from $1^{\text {st }}$ June 2020 to $14^{\text {th }}$ June 2020 .

Methodology: Total $n=124$ health care workers were assessed using Depression, Anxiety and stress scale(DASS 21). All health care workers who dealt with COVID 19 patients were approached and asked to participate after an informed consent. The scale was administered by a doctor who contacted the health care workers directly working with COVID 19 patients through video call and those previously working in this pandemic were contacted in person. The SPSS 20 package program was used for statistical analysis. Quantitative Variables like age were described as mean \pm SD. Cross tabulation and ChiSquared Test were used to identify which of the independent variables had significant influence on the outcome.

Results: Total 31(25\%) health care workers out of 124 exhibited features of depression whereas 49(39.5\%) health care workers showed features of anxiety. Total $n=26(21 \%)$ health care workers were found to be under stress. It was also seen that depression and anxiety was more common in females and health care workers working as residents, house officers and nursing assistants.

Conclusion: This study showed COVID 19 can cause significant distress in health care workers therefore all health care workers dealing with COVID 19 patient should be regularly monitored for psychological symptoms.

Keyword: Anxiety, Depression, Health care workers, Stress.

How to cite this Article:

kakar MS, Rauf S, Jalal U, Khan WA Gul I. The Emotional Burden of COVID 19 in Frontline Health Care Workers at A Tertiary Care Hospital in Pakistan. J Bahria Uni Med Dental Coll. 2021; 11(2): 60-64 DOI: https://doi.org/10.51985/LLFV9024

드- - - - - - - - - - - - - - - - - - - - - - - - - - - - This is an Open Access article distributed under the terms of the Creative Commons Attriution Non Commercial Liciense (http:// creativecommons/org/licences/by-nc/4.0) which permits unrestricted non commercial use, distribution and reproduction in any medium, provided the original work is properly cited.

\section{INTRODUCTION:}

Around 12.6 million people worldwide are currently effected by COVID 19 which has caused almost 560000 deaths around the globe. ${ }^{1}$ Pakistan received its first case on $26^{\text {th }}$ Feb 2020. Over the last 4 months these cases have risen to almost 243000 and the number of deaths is around $5100 .^{2}$ This

\begin{tabular}{l} 
Muhammad Siddique Kakar \\
I Consultant Psychiatrist, Department of Psychiatry \\
I PNS SHIFA Hospital, Karachi \\
Email: mskakar80@gmail.com \\
Shehzad Rauf \\
HOD Psychiatry, Department of Psychiatry \\
I PNS SHIFA Hospital, Karachi \\
I Umer Jalal \\
I Consultant Psychiatrist, Department of Psychiatry \\
Combined Military Hospital, Mangla \\
Waseem Ahmed Khan \\
I POD Surgery, Department of Surgery \\
I PNS SHIFA Hospital, Karachi \\
Isbah Gul \\
Consultant Psychiatrist, Department of Psychiatry \\
I PNS SHIFA Hospital, Karachi \\
I Received: 31-08-2020 \\
Accepted: 15-02-2021 \\
\hline
\end{tabular}

pandemic has affected health care workers both mentally and physically. The factors which have caused an increased psychological stress include high infection risk, over work, exhaustion, frustration, isolation and lack of contact with family and friends., ${ }^{3,4}$ These factors are further magnified when the doctors have to choose between whose lives to save associated with a decision to prioritize critical beds leading to an increased sense of responsibility and at times even guilt. These emotional challenges and moral injuries can have a long lasting psychological effect on health care workers. ${ }^{5}$ It has been seen the health care workers are facing multiple challenges in this crisis including an unknown etiological agent, unpredictability in symptoms, massive demand, and lack of resources, fear of contagion and a marked prevailing sense of helplessness. ${ }^{6}$ A study from Pakistan revealed that the biggest fears of health care workers include infecting family members, becoming a carrier, missing a diagnosis and complications of disease. ${ }^{7} \mathrm{~A}$ systematic review based on 13 studies showed a pooled prevalence of $23.2 \%$ and $22.8 \%$ for anxiety and depression respectively. It was also found to be more in females and nurses. ${ }^{8}$ A study from Wuhan in China revealed a prevalence of $12.7 \%$ of mild depressive features and $20.1 \%$ mild anxiety symptoms however the scores for perceived stress were 
markedly elevated in more than half (59\%) of the health care workers. This study also showed females to be more effected. ${ }^{9}$ A study looking into a tertiary care hospital found the prevalence of anxiety in medical staff was $23.04 \%$ and most of them were found to be mildly anxious $(16.09 \%)$ whereas stress disorders were found in $27.3 \%$ of medical staff. Anxiety and stress was found to be more common in females and in nurses. ${ }^{10}$ A Chinese survey based, region stratified study on 1257 health care workers revealed that $50.4 \%$ had depressive features, $44.6 \%$ had anxiety and $71.5 \%$ were in distress. Nurses, females and those working in Wuhan were found to be more effected. ${ }^{11}$ It has also been seen despite increased prevalence of psychological issues; health care workers do not often seek or receive mental health care which may be due to the fear of being labeled and stigmatized. ${ }^{12}$ A Pakistani study on frontline physicians found a $43 \%$ prevalence of anxiety/depression based on WHO self reporting questionnaire SRQ-20. ${ }^{13}$

This study has been designed to look into effects of COVID 19 on health care workers who are directly dealing with such patients. Our hypothesis is that dealing with COVID 19 patients has indirectly affected the mental health of health care workers. Hence; this study was aimed to assess the levels of depression, anxiety and stress in frontline health care workers dealing with COVID 19 patients.

\section{METHODOLOGY:}

This cross sectional study was conducted at PNS Shifa hospital Karachi from $1^{\text {st }}$ June 2020 to $14^{\text {th }}$ June 2020. The sample size was calculated by WHO sample size calculator with a confidence interval of $90 \%$ and was found to be 124 based on a Chinese study which showed higher levels of depression, anxiety and stress in frontline workers dealing with COVID 19 patients. ${ }^{10}$ Health care workers were enrolled into the study after informed consent and ethical approval from the ethical committee of PNS Shifa hospital with ERC number ERC/2020/psych/21. These health care workers were 20 to 50 years of age. Criteria that excluded health care workers from the study included non-consenting individuals and presence of psychiatric illness.

All health care workers who dealt with COVID 19 patients were approached. Assessment tools consisted of a data form (including age, gender, educational level, occupational status including doctors, nurses and paramedical staff and marital status). Depression, anxiety and stress were assessed by applying Depression, anxiety and stress scale(DASS 21). ${ }^{14}$ This quantitative scale measures the emotional state of the patient on the lines of depression, anxiety and perceived stress through 21 questions(7 questions each) which are answered on 5 severity levels. The total scores help to demarcate mild, moderate, severe and extremely severe levels of depression, anxiety and stress. The score achieved on the each scale is multiplied with 2 for final score. The scale was administered by a doctor who contacted the health care workers directly working with COVID 19 patients through video call and those previously working with COVID 19 patients were contacted in person. The SPSS 20 package program was used for statistical analysis. Quantitative Variables like age were described as mean \pm SD. Cross tabulation and Chi- Squared Test were used to identify which of the independent variables had significant influence on the outcome.

\section{RESULTS:}

There were 69(55.6\%) males and 55(44.4\%) females in this study. The mean age was $28.9 \pm 6.2$.DASS 21 score for depression were high in $31(25.0 \%)$ of health care workers. Within the scores for depression, it was seen that $19(15.4 \%)$ of health care workers were found to be mildly depressed, $05(4.0 \%)$ were moderately depressed and $05(4.0 \%)$ of health care workers had scores within severe range. Whereas $02(1.6 \%)$ participants were severely affected. The scores for anxiety revealed a total of $49(39.5 \%)$ health care workers to be anxious out of which $31(25.0 \%), 09(7.3 \%), 04(3.2 \%)$ and $05(4.0 \%)$ were found to be mild, moderate, severe and extremely severe respectively. On the stress scale it was seen that 26(21.0\%) health care workers were stressed. Among them 18(14.6\%), 4(3.2\%) and 4(3.2\%) were mild, moderate and severely stressed respectively. Table 1 shows the correlation of different factors with depressive features. The significant correlation was observed in case of gender $(\mathrm{P}=0.011)$, marital status $(\mathrm{P}=0.045)$ and appointment of health care workers $(\mathrm{P}=0.004)$ showing these features to be more in females and HCWs working as residents, house officers or Nursing assistants. Similarly table 2 shows a significant correlation of anxiety with gender $(\mathrm{P}=0.002)$, marital status $(\mathrm{P}=0.036)$ and appointment or type of health care workers $(\mathrm{P}=0.016)$ showing more occurrence in females and health care workers working as residents, house officers, nurses and nursing assistants. Regarding the relation of stress scores with different factors it was found to be significant only in the type of health care workers affecting such as residents, house officers and nursing assistants more $(\mathrm{P}=0.022)$ - as seen in table 3 .

\section{DISCUSSION:}

Our study showed a significant prevalence of depression $(25 \%)$, anxiety $(39.5 \%)$ and stress $(21 \%)$ within frontline health care workers dealing with COVID 19 patients. Most of the health care workers who were depressed showed moderately depressive features and depressive features were more existent in females, married health care workers and those working as residents or house officers. Whereas most of the anxious health care workers showed mild anxiety features and anxiety features were more prevalent in females and married health care workers. Similarly stressful features were also significantly prevalent in females. . A cross sectional study from a Chinese institute comparing the mental health of its medical and non medical staff found 
The Emotional Burden of COVID 19 in Frontline Health Care Workers at A Tertiary Care Hospital in Pakistan

Table 1- Demographics of patients with different levels of Depression severity

\begin{tabular}{|c|c|c|c|c|c|c|c|}
\hline \multirow{2}{*}{$\begin{array}{l}\text { Patient } \\
\text { Characteristics }\end{array}$} & \multicolumn{5}{|c|}{$\begin{array}{c}\text { Number of samples with DASS(Depression) Scores } \\
\text { according to severity }\end{array}$} & \multirow{2}{*}{$\begin{array}{c}\text { Mean total } \\
\text { DASS score } \\
\quad \pm \text { SD }\end{array}$} & \multirow{2}{*}{ P-Value } \\
\hline & $\begin{array}{c}\text { Normal } \\
(0-9)\end{array}$ & $\begin{array}{c}\text { Mild } \\
(10-13)\end{array}$ & $\begin{array}{c}\text { Moderate } \\
(14-20)\end{array}$ & \begin{tabular}{|l} 
Severe \\
$(21-27)$
\end{tabular} & $\begin{array}{c}\text { Very Severe } \\
(28+)\end{array}$ & & \\
\hline \multicolumn{8}{|l|}{ Gender } \\
\hline Male & $60(48.3 \%)$ & $05(4.0 \%)$ & $02(1.6 \%)$ & $02(1.6 \%)$ & $00(0.0 \%)$ & $7.9 \pm 3.6$ & \multirow{2}{*}{0.011} \\
\hline Female & $33(26.6 \%)$ & $14(11.2 \%)$ & $03(2.4 \%)$ & $03(2.4 \%)$ & $02(1.6 \%)$ & $10.8 \pm 6.7$ & \\
\hline \multicolumn{8}{|l|}{ Marital status } \\
\hline Single & $47(37.9 \%)$ & $06(4.8 \%)$ & $05(4.0 \%)$ & $03(2.4 \%)$ & $02(1.6 \%)$ & $9.9 \pm 6.6$ & \multirow{2}{*}{0.045} \\
\hline Married & $46(37.0 \%)$ & $13(10.4 \%)$ & $00(0.0 \%)$ & $02(1.6 \%)$ & $00(0.0 \%)$ & $8.5 \pm 3.6$ & \\
\hline \multicolumn{8}{|l|}{ Type of HCWs } \\
\hline Consultant & $11(8.8 \%)$ & 00 & 00 & 00 & 00 & $6.7 \pm 1.3$ & \multirow{5}{*}{0.004} \\
\hline Resident & $17(13.7 \%)$ & $06(4.8 \%)$ & 00 & 00 & 00 & $8.6 \pm 2.7$ & \\
\hline House Officers & $20(16.1 \%)$ & $02(1.6 \%)$ & $04(3.2 \%)$ & $04(3.2 \%)$ & $01(0.8 \%)$ & $12.1 \pm 8.1$ & \\
\hline Nurses & $09(7.2 \%)$ & 00 & 00 & 00 & 00 & $8.7 \pm 1.9$ & \\
\hline Nursing Assistants & $36(29.0 \%)$ & $04(3.2 \%)$ & $01(0.8 \%)$ & $01(0.8 \%)$ & $01(0.8 \%)$ & $8.2 \pm 5.0$ & \\
\hline
\end{tabular}

Table 2: Demographics of patients with different levels of Anxiety severity

\begin{tabular}{|c|c|c|c|c|c|c|c|}
\hline \multirow{2}{*}{$\begin{array}{l}\text { Patient } \\
\text { Characteristics }\end{array}$} & \multicolumn{5}{|c|}{$\begin{array}{c}\text { Number of samples with DASS(Anxiety) Scores } \\
\text { according to severity }\end{array}$} & \multirow{2}{*}{$\begin{array}{l}\text { Mean total } \\
\text { DASS score } \\
\quad \pm \text { SD }\end{array}$} & \multirow{2}{*}{ P-Value } \\
\hline & $\begin{array}{c}\text { Normal } \\
(0-7)\end{array}$ & $\begin{array}{l}\text { Mild } \\
(8-9)\end{array}$ & $\begin{array}{c}\text { Moderate } \\
(10-14)\end{array}$ & \begin{tabular}{|c|} 
Severe \\
$(15-19)$
\end{tabular} & $\begin{array}{c}\text { Very Severe } \\
(20+)\end{array}$ & & \\
\hline \multicolumn{8}{|l|}{ Gender } \\
\hline Male & $48(38.7 \%)$ & $19(15.3 \%)$ & $01(0.8 \%)$ & 00 & $01(0.8 \%)$ & $6.7 \pm 2.7$ & \multirow{2}{*}{0.002} \\
\hline Female & $27(21.7 \%)$ & $12(9.6 \%)$ & $08(2.7 \%)$ & $04(3.2 \%)$ & $04(3.2 \%)$ & $9.7 \pm 5.9$ & \\
\hline \multicolumn{8}{|l|}{ Marital status } \\
\hline Single & $38(30.6 \%)$ & $14(11.2 \%)$ & $06(4.8 \%)$ & 00 & $05(4.0 \%)$ & $8.6 \pm 5.7$ & \multirow{2}{*}{0.036} \\
\hline Married & $37(29.8 \%)$ & $17(13.7 \%)$ & $03(2.4 \%)$ & $04(3.2 \%)$ & $00(0.0 \%)$ & $7.4 \pm 3.2$ & \\
\hline \multicolumn{8}{|l|}{ Type of HCWs } \\
\hline Consultant & $10(8.0 \%)$ & $01(0.8 \%)$ & 00 & 00 & 00 & $5.8 \pm 1.0$ & \multirow{5}{*}{0.016} \\
\hline Resident & $10(8.0 \%)$ & $10(8.0 \%)$ & $01(0.8 \%)$ & $02(1.6 \%)$ & 00 & $7.8 \pm 3.2$ & \\
\hline House Officers & $18(14.5 \%)$ & $03(2.4 \%)$ & $05(4.0 \%$ & $02(1.6 \%)$ & $03(2.4 \%)$ & $9.8 \pm 6.3$ & \\
\hline Nurses & $07(5.6 \%)$ & $08(2.7 \%)$ & $01(0.8 \%)$ & 00 & 00 & $7.8 \pm 2.2$ & \\
\hline Nursing Assistants & $30(24.1 \%)$ & $09(7.2 \%)$ & $02(1.6 \%)$ & 00 & $02(1.6 \%)$ & $7.4 \pm 4.9$ & \\
\hline
\end{tabular}

that health care workers had 1.4 times higher level of fear and 2 times higher levels of depression and anxiety in the health care workers which was more prevalent in those directly dealing with COVID 19 patients. ${ }^{14}$ A short review based on 14 studies looking into the effects of COVID 19 on health care workers revealed that severe levels of anxiety and depression were found in $2.2 \%$ to $14.5 \%$ of all participants and it was dependent on the specialty of the health care workers and their proximity to COVID 19 patients. ${ }^{15}$ Another study comparing the effects of COVID 19 on medical personnel and non medical personnel found the prevalence of depression(12.2 vs. $9.5 \% ; p<0.04)$, ), anxiety ( 13.0 vs. $8.5 \%, p<0.01$ ), and insomnia (38.4 vs. $30.5 \%, p<0.01)$ to be higher in medical personnel. It was also revealed that being female and working close to COVID 19 patients were significant risk factors in medical personnel for depression and anxiety. ${ }^{16} \mathrm{~A}$ study in 2004 looking into the effect of SARS epidemic found that the it lead to increased levels of stress in patients which also included health care workers(39\%) who showed higher levels of fatigue and were particularly more worried about their health. ${ }^{17}$ In 2009 a study which assessed the long term effects of SARS epidemic revealed that even about 31 to 50 months after the infection, survivors were still diagnosed with PTSD-post traumatic stress disorder (54.5\%), depression(39\%) and panic disorder(32.5\%), which was a marked increase from their pre-infection prevalence of any psychiatric diagnoses which was just $3 \% .{ }^{18}$ A study in 2011 on 257 subjects showed 
Muhammad Siddique Kakar, Shehzad Rauf, Umer Jalal, Waseem Ahmed Khan, Isbah Gul

Table 3: Demographics of patients with different levels of Stress severity

\begin{tabular}{|c|c|c|c|c|c|c|c|}
\hline \multirow{2}{*}{$\begin{array}{l}\text { Patient } \\
\text { Characteristics }\end{array}$} & \multicolumn{5}{|c|}{$\begin{array}{c}\text { Number of samples with DASS(Stress) Scores } \\
\text { according to severity }\end{array}$} & \multirow{2}{*}{$\begin{array}{l}\text { Mean total } \\
\text { DASS score } \\
\quad \pm \text { SD }\end{array}$} & \multirow{2}{*}{ P-Value } \\
\hline & $\begin{array}{c}\text { Normal } \\
(0-14)\end{array}$ & \begin{tabular}{c|c|} 
Mild \\
$(15-18)$
\end{tabular} & $\begin{array}{c}\text { Moderate } \\
(19-25)\end{array}$ & \begin{tabular}{|l|} 
Severe \\
$(26-33)$
\end{tabular} & $\begin{array}{c}\text { Very Severe } \\
(34+)\end{array}$ & & \\
\hline \multicolumn{8}{|l|}{ Gender } \\
\hline Male & $57(45.9 \%)$ & $09(7.2 \%)$ & $03(2.4 \%)$ & 00 & 00 & $11.5 \pm 3.7$ & \multirow{2}{*}{0.106} \\
\hline Female & $41(33.0 \%)$ & $09(7.2 \%)$ & $01(0.8 \%)$ & $04(3.2 \%)$ & 00 & $13.2 \pm 5.9$ & \\
\hline \multicolumn{8}{|l|}{ Marital status } \\
\hline Single & $52(41.9 \%)$ & $05(4.0 \%)$ & $03(2.7 \%)$ & $03(2.7 \%)$ & 00 & $12.2 \pm 5.3$ & \multirow{2}{*}{0.117} \\
\hline Married & $46(37.0 \%)$ & $13(10.9 \%)$ & $01(0.8 \%)$ & $01(0.8 \%)$ & 00 & $12.3 \pm 4.5$ & \\
\hline \multicolumn{8}{|l|}{ Type of HCWs } \\
\hline Consultant & $11(8.8 \%)$ & 00 & 00 & 00 & 00 & $9.2 \pm 1.6$ & \multirow{5}{*}{0.022} \\
\hline Resident & $15(12.0 \%)$ & $08(6.4 \%)$ & 00 & 00 & 00 & $12.5 \pm 3.5$ & \\
\hline House Officers & $24(19.3 \%)$ & $01(0.8 \%)$ & $03(2.7 \%)$ & $03(2.7 \%)$ & 00 & $14.0 \pm 6.5$ & \\
\hline Nurses & $13(10.4 \%)$ & $03(2.7 \%)$ & 00 & 00 & 00 & $12.2 \pm 3.4$ & \\
\hline Nursing Assistants & $35(27.4 \%)$ & $06(4.8 \%)$ & $01(0.8 \%)$ & $01(0.8 \%)$ & 00 & $11.7 \pm 4.8$ & \\
\hline
\end{tabular}

that seropositivity for coronaviruses was associated with a history of mood disorders and it suggested that coronavirus infections can cause mood disorders. ${ }^{19}$ The pro-inflammatory effects of the virus which involves the release of cytokines including Interleukin IL $1 \mathrm{~b}$ and IL 6 may have a neuroinflammatory effect leading to neuropsychiatric effects. ${ }^{20}$ A study from Singapore assessing effect of COVID19 on 470 employees of 2 tertiary care hospitals found that $14.5 \%$ had features of anxiety, $8.9 \%$ had depressive features and $6.6 \%$ were found to be stressed. ${ }^{21}$ A study from Pakistan assessing the stress coping strategies of frontline health workers found that HCWs used limited media exposure, limited sharing of COVID details, religious coping and altruism as their coping strategies. ${ }^{22}$ A study from Hubei China involving 534 frontline medical staff showed that they were anxious regarding their safety and the safety of their families and reported psychological effects from reports of mortality from COVID-19 infection. ${ }^{23}$ A study from Liberia during the Ebola epidemic looking into the coping mechanisms of health care workers showed that There were several important coping strategies which could help the medical staff deal with the epidemic psychologically including being sustained by religion, a sense of serving their country and community, and peer and family support. External factors which could improve their coping included: training which built health worker confidence in providing care; provision of equipment to do their job safely; workshops that provided ways to deal with the stigma associated with being a health worker; and the risk allowance, which motivated staff to work in facilities and provided an additional income source. ${ }^{24}$ There are some limitations of this study. The study was carried out during the pandemic and we were careful not to distract participants from emergency work in result of which interviews were often paused or interrupted because the participants had to attend some other emergency duties. The study lacks generalizability, and only explores the perspectives of health care workers dealing directly with COVID 19 patients. It cannot ascertain the perspectives of other health care workers not working directly with COVID 19 patients as well as administrators and patients. This study did not explore findings of health care workers from other hospitals that may have had different experiences of the pandemic and different coping mechanisms, which need exploration.

\section{CONCLUSION:}

This study has helped us understand the effects of COVID 19 on frontline health care workers in a tertiary care hospital in Pakistan. Higher scores on DASS scale suggested that health care workers need regular monitoring and detailed psychiatric interviews to further establish any worsening of symptoms. Administrators of hospitals should focus on the psychological state of their frontline health care workers and actively conduct psychological counseling. Adequate and timely psychological interventions could help reduce the psychosocial problems that may develop in the future.

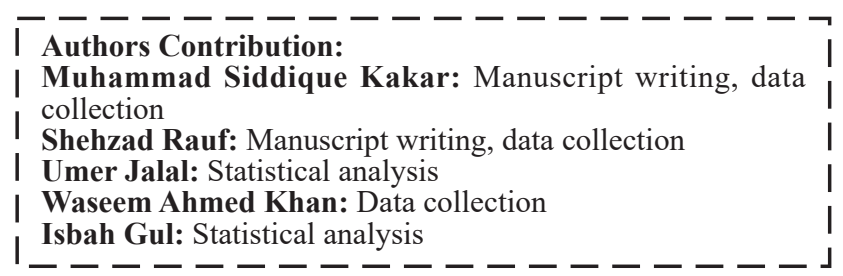

\section{REFERANCES:}

1. Worldometer Coronavirus pandemic reported cases and deaths. Available at: www.worldometers.info/coronavirus/ coronaviruscases/. (Accessed July 11,2020.)

2. Government of Pakistan. Coronavirus in Pakistan. Available at: http://covid.gov.pk/. (Accessed July 11, 2020.) 
3. Kang L, Li Y, Hu S, Chen M, Yang C, Yang BX et al. The mental health of medical workers in Wuhan, China dealing with the 2019 novel coronavirus. The Lancet Psychiatry. 2020;7(3):e14. doi: 10.1016/s2215-0366(20)30047-x

4. Chen Q, Liang M, Li Y, Guo J, Fei D, Wang L et al. Mental health care for medical staff in China during the COVID-19 outbreak. The Lancet Psychiatry. 2020;7(4):e15-e16. doi:10.1016/s2215-0366(20)30078-X

5. Greenberg N, Docherty M, Gnanapragasam S, Wessely S. Managing mental health challenges faced by healthcare workers during covid-19 pandemic.BMJ.2020;368:m1211. doi: https://doi.org/10.1136/bmj.m1211

6. Vieta E, Pérez V, Arango C. Psychiatry in the aftermath of COVID-19. Revista de Psiquiatría y Salud Mental. 2020;13(2):105-110. doi:https: 10.1016/j.rpsm.2020.04.004

7. Urooj U, Ansari A, Siraj A, Khan S, Tariq H. Expectations, Fears and Perceptions of doctors during Covid-19 Pandemic. Pakistan Journal of Medical Sciences. 2020;36(COVID19S4):S37-S42. Doi: 10.12669/pjms.36.covid19-s4.2643

8. Pappa S, Ntella V, Giannakas T, Giannakoulis V, Papoutsi E, Katsaounou P. Prevalence of Depression, Anxiety, and Insomnia Among Healthcare Workers During the COVID-19 Pandemic: A Systematic Review and Meta-Analysis. Brain Behave Immun. 2020.88;901-7.Doi:10.2139/ssrn.3594632

9. Du J, Dong L, Wang T, Yuan C, Fu R, Zhang L et al. Psychological symptoms among frontline healthcare workers during COVID-19 outbreak in Wuhan. General Hospital Psychiatry. 2020.doi:10.1016/j.genhosppsych.2020.03.011 [Epub ahead of print]

10. Huang JZ, Han MF, Luo TD, Ren AK, Zhou XP. Mental health survey of medical staff in a tertiary infectious disease hospital for COVID-19. Zhonghua lao Dong wei Sheng zhi ye Bing za zhi $=$ Zhonghua Laodong Weisheng Zhiyebing Zazhi $=$ Chinese Journal of Industrial Hygiene and Occupational Diseases. 2020 Mar;38(3):192-5. DOI: 10.3760/cma.j.cn121094-20200219-00063.

11. Lai J, Ma S, Wang Y, Cai Z, Hu J, Wei N, et al. Factors Associated With Mental Health Outcomes Among Health Care Workers Exposed to Coronavirus Disease 2019. JAMA Netw Open. 202003 2;3(3):e203976. doi;10.1001/ jamanetworkopen.2020.3976

12. Xiang YT, Yang Y, Li W, Zhang L, Zhang Q, Cheung T,et al. Timely mental health care for the 2019 novel Coronavirus outbreak is urgently needed. Lancet Psychiatry. 2020;7:228-9. doi: 10.1016/s2215-0366(20)30046-8

13. Amin F,Sharif S, Saeed R, Durrani N,Jilani D. COVID-19 Pandemic- Knowledge, Perception, Anxiety and Depression Among Frontline Doctors of Pakistan. Research Square. 2020. doi: https://doi.org/10.21203/rs.3.rs-27559/v1
14. Lovibond, S.H. and Lovibond, P.F. (1995) Manual for the Depression Anxiety Stress Scales. 2nd Edition, Psychology Foundation, Sydney.

15. Lu W, Wang H, Lin Y, Li L. Psychological status of medical workforce during the COVID-19 pandemic: A cross-sectional study. Psychiatry Research. 2020;288:112936. doi:10.1016/j.psychres.2020.112936

16. Bohlken J, Schömig F, Lemke MR, Pumberger M, RiedelHeller SG. [COVID-19 Pandemic: Stress Experience of Healthcare Workers - A Short Current Review]. Psychiatr Prax. 2020;47(4):190-7. doi:10.1055/a-1159-5551.

17. Zhang W, Wang K, Yin L, Zhao W, Xue Q, Peng M,et al: Mental Health and Psychosocial Problems of Medical Health Workers during the COVID-19 Epidemic in China. Psychother Psychosom 2020;89:242-50. doi: 10.1159/000507639

18. Chua S, Cheung V, McAlonan G, Cheung C, Wong J, Cheung E et al. Stress and Psychological Impact on SARS Patients during the Outbreak. The Canadian Journal of Psychiatry. 2004;49(6):385-90. doi:10.1177/070674370404900607.

19. Lam M. Mental Morbidities and Chronic Fatigue in Severe Acute Respiratory Syndrome Survivors. Archives of Internal Medicine.2009;169(22):2142.doi 10.1001/archinternmed. 2009.384

20. Okusaga O, Yolken R, Langenberg P, Lapidus M, Arling T, Dickerson $F$ et al. Association of seropositivity for influenza and coronaviruses with history of mood disorders and suicide attempts. Journal of Affective Disorders. 2011;130(1-2):220225. doi: 10.1016/j.jad.2010.09.029

21. Shi Y, Wang Y, Shao C, Huang J, Gan J, Huang X et al. COVID-19 infection: the perspectives on immune responses. Cell Death \& Differentiation. 2020;27(5):1451-1454. doi:10.1038/s41418-020-0530-3

22. Tan BY, Chew NW, Lee GK, Jing M, Goh Y, Yeo LL et al. Psychological impact of the COVID-19 pandemic on health care workers in Singapore. Ann Intern Med. 2020;M20-1083 DOI:10.7326/M20-1083.

23. Munawar K, Choudhry FR. Exploring Stress Coping Strategies of Frontline Emergency Health Workers dealing Covid-19 in Pakistan: A Qualitative Inquiry. American Journal of Infection Control. 2020 Jul 7. doi.org/10.1016/j.ajic.2020.06.214 [Epub ahead of print]

24. Cai H, Tu B, Ma J, Chen L, Fu L, Jiang Y,et al. Psychological impact and coping strategies of frontline medical staff in Hunan between January and March 2020 during the outbreak of Coronavirus disease 2019 (COVID-19) in Hubei, China. Med Sci Monit. 2020, 26:e924171. Doi:10.12659/ MSM.924171 